\title{
Timed Inspiratory Effort Index, a New Diagnostic Method to Assess Endurance and Inspiratory Muscle Strength in Patients under Mechanical Ventilation
}

\author{
Leonardo Cordeiro de Souza ${ }^{1,2,3 *}$
}

${ }^{1}$ Medical Science Post-graduation Program, Fluminense Federal University, Niteroi, RJ, Brazil

${ }^{2}$ Physiotherapy School, Estacio de Sa University, RJ, Brazil

${ }^{3}$ Physiotherapy Service, Hospital \& Clínica Sao Goncalo and Hospital Icarai, RJ, Brazil

\begin{abstract}
Introduction: Mechanical ventilation is a critical component of modern intensive care medicine, but the process of discontinuing mechanical ventilation could be difficult in some cases. Several studies demonstrated that the combination of diaphragmatic inactivity and mechanical ventilation periods over than 18 hours is associated with atrophy of human diaphragm myofibers. Thus, the disuse atrophy of human diaphragm myofibers could be a major contributor for weaning failures.
\end{abstract}

Indeed, its proper assessment of the respiratory muscle impairment depends on the use of appropriate tests. The predicting weaning indexes are still the most commonly used tests in clinical practice at ICUs around the world, because they are more widely known and easy to use in different diseases.

Objective: The aim of the present article is to describe advantages, procedures, and clinical applicability of a new method called timed inspiratory effort index, or TIE index, to assess inspiratory muscle strength and specifically address the diagnosis of muscle fatigue in patients under mechanical ventilation.

Methods: This short review about a new method to assess endurance and inspiratory muscle strength of patients with respiratory weakness and undergoing weaning from mechanical ventilation.

Main recommendations: The analysis of respiratory muscle function through the TIE method translates a new feature to the intensive care fast, easy, accurate, reproducible and secure. In addition, to aid in the differential diagnosis of respiratory muscle fatigue directly predict weaning, may lead the most appropriate respiratory muscle training in prolonged weaning patients.

Conclusion: In summary, nowadays, the TIE index can be considered one of the most appropriate methods to evaluate the various interactions in a critical patient under mechanical ventilation. Therefore, TIE index performance as a weaning predictor is among the best rates ever reported in literature.

Keywords: Respiratory muscles; Muscle weakness; Diaphragm; Respiratory function tests; Diagnostic tests

\section{Introduction}

Mechanical ventilation is a critical component of modern intensive care medicine, but the process of discontinuing mechanical ventilation could be difficult [1]. Several studies have shown that the combination of diaphragmatic inactivity and mechanical ventilation for periods more than 18 hours is associated with atrophy of human diaphragm myofibers [2]. Thus, the disuse atrophy of human diaphragm myofibers could be a major contributor to the weaning problems that occur in some patients [3].

An alarming data has related patients requiring prolonged mechanical ventilation, defined as more than 21 days [4-6], account for more than $13 \%$ of ventilated patients [7] and $37 \%$ of intensive care unit (ICU) costs [8]. Because of changes in US reimbursement practices, these patients are usually transferred to specialized weaning centers, also known as long term acute care hospitals $[9,10]$, in which the costs increased by $267 \%$, reaching $\$ 1.3$ billion in 2006 [11]. With the US population aging, demands for intensivist services are predicted to increase $38 \%$ over the next decade [12]. Consequently, the number of ICU patients in prolonged weaning ventilation will increase substantially [13]. To this specific group of patients, the successful weaning is around $51 \%$, and the mortality rate is around $66 \%$ in one year [14].
The aim of the present article is to describe advantages, procedures, and clinical applicability of new method called timed inspiratory effort index, or TIE index, to assess inspiratory muscle strength and specifically address the diagnosis of muscle fatigue in patients under mechanical ventilation.

\section{Main considerations about predicting weaning respiratory indexes}

The predictor weaning indexes are used in clinical practice of ICUs around the world. Two of them, the ratio of respiratory rate by the tidal volume or rapid shallow breathing index $(\mathrm{f} / \mathrm{Vt})$ and maximum inspiratory pressure (MIP), were incorporated into the routine of most

*Corresponding author: Leonardo Cordeiro de Souza, Chief, Physiotherapy Service of Icarai Hospital, Rua Marques de Parana, 233-5o. andar., CEP 24030-215-Centro, Niteroi, RJ, Brazil, Tel: 55(21)3176-5000 R: 5306; E-mail: leonardo.uti@gmail.com

Received October 15, 2016; Accepted November 24, 2016; Published November 28, 2016

Citation: de Souza LC (2016) Timed Inspiratory Effort Index, a New Diagnostic Method to Assess Endurance and Inspiratory Muscle Strength in Patients under Mechanical Ventilation. J Pulm Respir Med 6: 382. doi: 10.4172/2161105X.1000382

Copyright: ( 2016 de Souza LC. This is an open-access article distributed under the terms of the Creative Commons Attribution License, which permits unrestricted use, distribution, and reproduction in any medium, provided the original author and source are credited. 
units and are recommended by the $6^{\text {th }}$ consensus American Thoracic Society (ATS) consensus and European Respiratory Society (ERS) on the subject [2]. MIP and f/Vt indexes are mainly recommended for patients with weaning difficulty $[2,15]$.

In fact, the MIP was the first respiratory rate reported in the literature as a weaning predictor. However, due to a short observation period, employment of an analog vacuometer without unidirectional valve and the lack of standardization, the performance as a weaning predictor were not too good in most studies [16-22].

The MIP evaluation in patients under mechanical ventilation is traditionally performed with airway occlusion by 20 seconds. This strategy aims to retain $\mathrm{PaCO}_{2}$ during the occlusion period to stimulate the respiratory center, independent of voluntary brain control. Examinator can observe every inspiratory incursion, and the increasing stimulus, until reaching the maximum inspiratory peak [23].

An intrinsic obstacle for this strategy is the necessity to monitor the performance time. Hardly, only one observer could evaluate each inspiratory capacity incursion and, at the same time, monitor the duration of the procedure. In 2002, for example, Soo Hoo and Park employed airway occlusion for up to 20 seconds and measured the MIP with analog vacuometer. It was observed that, although professionals from the same team performed the MIP measures, their results were not homogeneous. Multiple consecutive measures were required to improve the accuracy of the test [24].

Due to a number of factors, such as study design (prospective or retrospective), weaning method and definition of success or failure, the MIP measurement accuracy as a weaning predictor has varied widely among different studies. In general, studies have shown sensitivity to approximately $80 \%$ cropping values above -30 to $-20 \mathrm{~cm} \mathrm{H}_{2} \mathrm{O}[17,18,23]$. Since success in weaning depends on other factors, specificity has been very low in all studies (approximately 25\%) meaning that patients who fail in weaning do not necessarily have a reduced MIP [25].

In an attempt to make MIP measure more reproducible, in 1986, Marini et al. [16] after the evaluation of 20 patients artificially ventilated, described the method of the expiratory unidirectional valve, a device coupled to the opening of the airways, which only allowed exhalation. Thus, patients were required to make a progressively greater inspiratory effort as they approached the residual volume when the MIP observed could reach the maximum amount that patient could generate. Despite this result, the MIP values measured in critically ill patients are usually underestimated and have low reproducibility [26].

The identification of reliable forms of assessment of respiratory muscle strength may contribute to better monitoring of mechanical ventilation weaning process and the establishment of treatment strategies. In 2007, Guimaraes et al. [27] evaluated 30 patients artificially ventilated with an analog vacuometer, comparing the simple occlusion method with the unidirectional valve mentioned above in 20,30 and 40 seconds. They concluded that in non-cooperative patients, larger MIP was obtained with the method of the unidirectional valve occlusion during 40 seconds compared to the other evaluated protocols.

In 212, de Souza et al. [28] evaluated MIP values under unidirectional valve, for 60 seconds period using a digital vacuometer. The maximum value during the observation period occurred more often between 40 and 60 seconds, suggesting that the observation time is a determinate factor to achieve the MIP [28].

Therefore, a longer time of inspiratory occlusion with the use of a unidirectional valve to reach the peak stress is needed [28]. Thus,

the search for an index with better weaning predictor consider the combination of parameters: measurement of maximal inspiratory muscle strength with the time that it is achieved in a period not exceeding 60 seconds of airway occlusion, to idealize the timed inspiratory effort index, or TIE index (Figure 1).

In two other publications, the TIE index showed better accuracy than the other indexes cited in the literature. In which not only pointed out the most appropriate time to wean, but also showed precisely the weakness and low resistance to fatigue, especially in patients with prolonged mechanical ventilation ( $\mathrm{ROC} A \mathrm{AUC}=0.90$ ), and neurological and neuromuscular diseases (ROC AUC=0.96) [21,22]. Inferring the fact that, this innovative method the evaluation of respiratory muscle system, you can also follow the rehabilitation process of the inspiratory muscles of patients in difficult and prolonged weaning [22].

Despite promising initial results with the TIE ratio, we are currently developing the study of its variability and intra and inter-observer reproducibility to assess whether the examination only once reflects the actual patient's condition in ICU [29]. The use of reproducibility evaluation method is needed to improve training and technical execution performance. This approach can positively influence the assessment results and decision-making at the bedside.

\section{Latest results about TIE index}

In the study of de Souza et al. [29], the results were excellent, in which the coefficients of variation of Bland-Altman and Kappa agreement were respectively $15.78 \%$ and 0.88 for intra-observer group, and $17.38 \%$ and 0.91 for inter-observer group. These values show a low percentage of variability and excellent agreement between measurements. Again, the method described showed an excellent characteristic of reproducibility [29].

The areas under the ROC curve of the TIE index evaluated in groups intra-observer was (AUC of 0.97 vs. $0.94, \mathrm{P}=0.97$ ) and inter-

\section{FLOWCHART ABOUT TIE METHOD}

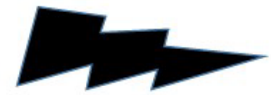

Standart method with airway occlusion until $60 \mathrm{sec}$.

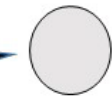

$1^{\text {a }}$ Progressive stimulation with increase $\mathrm{PaCO} 2$ level In respiratory center

\section{$2^{\mathrm{a}}$ increased stimulus response} by phrenic nerve versus time

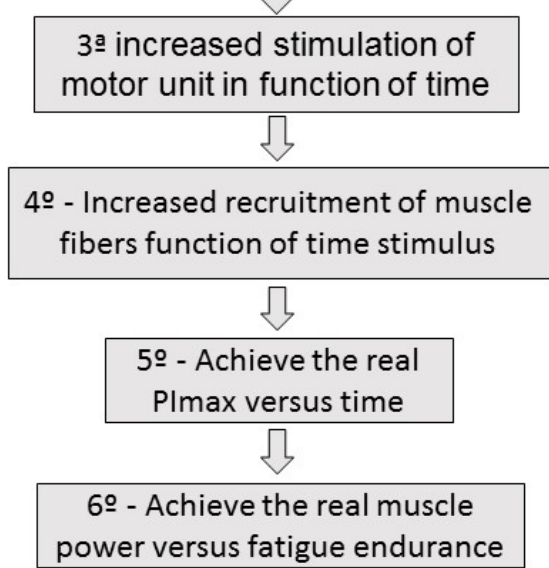

Figure 1: Flowchart about the standard TIE method and steps to achieve the real PImax and fatigue endurance. 
observer was (AUC of 0.94 vs. $0.91, \mathrm{P}=0.55$ ) to predict the weaning outcome. No significant statistical differences were found between the areas of ROC curve in both groups.

The TIE index shows that both the intra as in inter-group has no values statistical differences between the first and second exam. This fact, confirms the proposed method is not influenced both by examined and by the examiner, in which providing greater reliability and applicability for the implementation of the proposed examination. Therefore, the TIE index can be validated for the prediction of weaning, and it is a great tool for clinical utility [29].

\section{Procedures}

\section{How to measure the TIE index?}

For TIE index measurement is a digital vacuometer required, with a scale of at least $-200 \mathrm{~cm} \mathrm{H}_{2} \mathrm{O}$ increment of $1 \mathrm{~cm} \mathrm{H}_{2} \mathrm{O}$ and $100 \mathrm{~ms}$ time interval for each pressure measurement. It is essential that the patient could be monitored throughout the examination process for a reliable assessment. Due to the fact that the test in question exposes the patient to a large respiratory effort with possible reduction in oxygenation. Thus, for an appropriate measure of the TIE ratio, the patient should be positioned supine with the head elevated between $45^{\circ}$ and $60^{\circ}$, the hyper insufflated cuff to prevent leaks, clean endotracheal tube, and hyper oxygenation for two minutes with fraction of inspired oxygen $\left(\mathrm{FiO}_{2}\right)$ up to $100 \%[21,22]$.

After Hyper oxygenation, disconnecting the ventilator will be held and, after 10 seconds of spontaneous breathing, manually will be attached to the end of a normal expiration (at functional residual capacity) the artificial airway connector of the digital vacuometer, occluded keeping the airways during an interval of 60 seconds, recording the values corresponding to each inspiratory effort $[21,22]$.

The TIE ratio is calculated as the ratio between maximal inspiratory pressure, and the time to reach it for 60 seconds of observation. For successful weaning values, greater than $1.0 \mathrm{~cm} \mathrm{H}_{2} \mathrm{O} / \mathrm{s}$ is needed. A typical record of inspiratory pressures by time is shown in Figure 2 [21,22].

\section{Clinical applicability}

The determination of TIE index in patients under mechanical ventilation is important in the diagnosis of inspiratory muscle weakness, which can occur in pulmonary, cardiac, sepsis, neuromuscular diseases and others. In addition, the measurement of TIE index can aid in the differential diagnosis of dyspnea and obstructive lung disease of unknown origin; in assessing response to physiotherapy and rehabilitation; in prescribing and monitoring respiratory muscle training; and in critically ill patients in assessing the possibility and success of weaning from mechanical ventilation [30].

The better performance of the TIE index in the special article did not come as a surprise considering that the index is derived from parameters (respiratory drive and time to response), which can be crucially impaired in patients with muscle weakness acquired in ICU. This finding may be critical to weaning prediction in such patients in which the performance of other indexes like f/Vt, MIP and P0.1 are recognized to be poor $[21,22,29,30]$

In summary, nowadays, the TIE index can be considered the more adequate to evaluate the various interactions in a critical patient on ventilation mechanical. Finally, we confirm that your performance as a weaning predictor is among the best rates ever reported in the literature $[21,22,29,30]$.

\section{What is the TIE index?}

$\mathrm{R}: \mathrm{TIE}=$ Maximal peak $/$ time to achieve the inspiratory peak

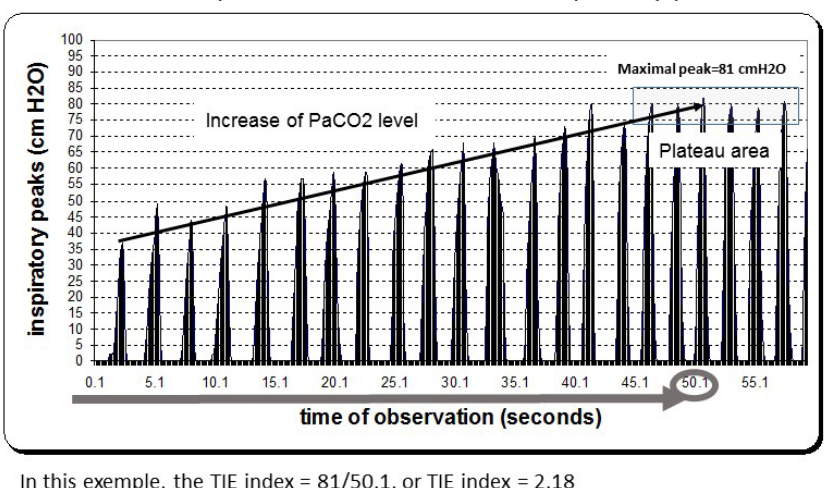

Figure 2: A typical graph record of inspiratory pressures by time showing the end stage of TIE method to achieve the maximal peak and the calculus of TIE index.

\section{Advantages and recommendations}

The respiratory muscle impairment is present not only in respiratory diseases but also in various other diseases and especially in critical ill patients. Indeed, its proper assessment depends on the use of appropriate tests. The predicting weaning indexes are still the most commonly used tests in clinical practice at ICU, because they are more widely known and because of their ease of use in different diseases.

Therefore, the advantages to the analysis of respiratory muscle function through the TIE method translates a new feature to the intensive care fast, easy, accurate, reproducible and secure. In addition, It is recommend the use of TIE method to the differential diagnosis of respiratory muscle fatigue to directly predict weaning, may lead the most appropriate respiratory muscle training in prolonged weaning patients $[21,22,30]$.

\section{Disadvantage and limitation}

All patients with the considerations ahead, must be exclusion criteria to measure the TIE index: tracheal stenosis, intracranial pressure $>20 \mathrm{mmHg}$, use of sedation, agitation, autonomic nervous system dysautonomia, severe hypoxemia, overt cardiac failure or hemodynamic instability, and signs of systemic infection/reinfection during the weaning process $[21,22]$.

The limitation to measure of TIE index will be in the use of digital vacuometer. This device must has a range 0 to $300 \mathrm{~cm} \mathrm{H}_{2} \mathrm{O}$ with a $1 \mathrm{~cm}$ $\mathrm{H}_{2} \mathrm{O}$ interval, and is designed to perform measurements each $100 \mathrm{~ms}$ $[20,21,22]$.

\section{Conclusion}

In summary, nowadays, the TIE index can be considered one of the most appropriate methods to evaluate the various interactions in a critical patient under mechanical ventilation. Therefore, the performance of TIE index as a weaning predictor is among the best rates ever reported in literature.

Finally, in near future, patients with strongly suspect of ventilatory muscle weakness and great difficulty of understand these wining events, will undergo in additional assessment with the new TIE method, and gone have a correct individualized treatment target. 
Citation: de Souza LC (2016) Timed Inspiratory Effort Index, a New Diagnostic Method to Assess Endurance and Inspiratory Muscle Strength in Patients under Mechanical Ventilation. J Pulm Respir Med 6: 382. doi: 10.4172/2161-105X.1000382

\section{References}

1. Laghi F, Cattapan SE, Jubran A, Parthasarathy S, Warshawsky P, et al. (2003) Is weaning failure caused by low-frequency fatigue of the diaphragm? Am J Respir Crit Care Med 167: 120-127.

2. Boles JM, Bion J, Connors A, Herridge M, Marsh B, et al. (2007) Weaning from mechanical ventilation. Eur Respir J 29: 1033-1056.

3. Levine S, Nguyen T, Taylor N, Friscia ME, Budak MT, et al. (2008) Rapid disuse atrophy of diaphragm fibers in mechanically ventilated humans. $N$ Engl J Med 358: 1327-1335.

4. Scheinhorn DJ, Hassenpflug MS, Votto JJ, Chao DC, Epstein SK, et al. (2007) Post-ICU mechanical ventilation at 23 long-term care hospitals: a multicenter outcomes study. Chest 131: 85-93.

5. Scheinhorn DJ, Chao DC, Stearn-Hassenpflug M, LaBree LD, Heltsley DJ (1997) Post-ICU mechanical ventilation: treatment of 123 patients at a regional weaning center. Chest 111: 1654-1659.

6. Carson SS, Garrett J, Hanson LC, Lanier J, Govert J, et al. (2008) A prognostic model for one-year mortality in patients requiring prolonged mechanical ventilation. Crit Care Med 36: 2061-2069.

7. Stauffer JL, Fayter NA, Graves B, Cromb M, Lynch JC, et al. (1993) Survival following mechanical ventilation for acute respiratory failure in adult men. Chest 104: $1222-1229$

8. Wagner DP (1989) Economics of prolonged mechanical ventilation. Am Rev Respir Dis 140: S14-S18.

9. Seneff MG, Wagner D, Thompson D, Honeycutt C, Silver MR (2000) The impact of long-term acute-care facilities on the outcome and cost of care for patients undergoing prolonged mechanical ventilation. Crit Care Med 28: 342-350.

10. Polverino E, Nava S, Ferrer M, Ceriana P, Clini E, et al. (2010) Patients' characterization, hospital course and clinical outcomes in five Italian respiratory intensive care units. Intensive Care Med 36: 137-142

11. Kahn JM, Benson NM, Appleby D, Carson SS, Iwashyna TJ (2010) Long-term acute care hospital utilization after critical illness. JAMA 303: 2253-2259.

12. Angus DC, Kelley MA, Schmitz RJ, White A, Popovich J Jr (2000) Committee on Manpower for Pulmonary and Critical Care Societies (COMPACCS). Caring for the critically ill patient: current and projected workforce requirements for care of the critically ill and patients with pulmonary disease: can we meet the requirements of an aging population? JAMA 284: 2762-2770.

13. Kahn JM (2010) The evolving role of dedicated weaning facilities in critical care. Intensive Care Med 36: 8-10.

14. Jubran A, Grant BJB, Duffner LA, Collins EG, Lanuza DM, et al. (2013) Effect of Pressure Support vs Unassisted Breathing through a Tracheostomy Colla on Weaning Duration in Patients Requiring Prolonged Mechanical Ventilation. A Randomized Trial. JAMA 309: 671-677.

15. Goldwasser R, Farias A, Freitas EE, Saddy F, Amado V, et al. (2007) Mechanical ventilation of weaning interruption. J Bras Pneumol 33: S128-S136.
16. Marini JJ, Smith TC, Lamb V (1986) Estimation of inspiratory muscle strength in mechanically ventilated patients: the measurement of maximal inspiratory pressure. J Crit Care Med 1: 32-38.

17. Yang KL, Tobin MJ (1991) A prospective study of indexes predicting the outcome of trials of weaning from mechanical ventilation. N Engl J Med 324 1445-1450.

18. Sassoon CS, Mahutte CK (1993) Airway occlusion pressure and breathing pattern as predictors of weaning outcome. Am Rev Respir Dis 148: 860-866.

19. Caruso P, Friedrich C, Denari SD, Ruiz SAL, Deheinzelin D (1999) The unidirectional valve is the best method to determine maximal inspiratory pressure during weaning. Chest 115: 1096-1101.

20. de Souza LC, de Silva CT Jr, Almeida JR, Lugon JR (2012) Comparison of maximal inspiratory pressure, tracheal airway occlusion pressure, and its ratio in the prediction of weaning outcome: impact of the use of a digital vacuometer and the unidirectional valve. Respir Care 57: 1265-1290.

21. de Souza LC, Guimaraes FS, Lugon JR (2015) The Timed Inspiratory Effort: A Promising Index of Mechanical Ventilation Weaning for Patients With Neurologic or Neuromuscular Diseases. Respir Care 60: 1-8.

22. de Souza LC, Guimarães FS, Lugon JR (2015) Evaluation of a new index of mechanical ventilation weaning: the timed inspiratory effort. J Intensive Care Med 30: 37-43.

23. Sahn SA, Lakshminarayan S (1973) Bedside criteria for discontinuation of mechanical ventilation. Chest 63: 1002-1005.

24. Soo Hoo GW, Park L (2002) Variations in the measurement of weaning parameters: a survey of respiratory therapists. Chest 121: 1947-1955.

25. Epstein SK (2002) Decision to extubate. Intensive Care Med 28: 535-546.

26. Multz AS, Aldrich TK, Prezand DJ, Karpel JP, Hendler JM (1990) Maximal inspiratory pressure is not a reliable test of inspiratory muscle strength in mechanically ventilated patients. Am Rev Respir Dis 142: 529-532.

27. Guimaraes FS, Alves FF, Constantino SS, Dias CM, Menezes SLS (2007) Maximal inspiratory pressure evaluation among non-cooperative critical patients: comparison between two methods. Rev Bras Fisioter 11: 233-238.

28. de Souza LC, de Silva CT Jr, Lugon JR (2012) Evaluation of the inspiratory pressure using a digital vacuometer in mechanically ventilated patients: analysis of the time to achieve the inspiratory peak. Respir Care 57: 257-262.

29. de Souza HLLC, Neto AES, Serejo ALC, Sertã BL, de Sá A, et al. (2016) The new index TIE: analysis of intra and inter-observer reproducibility of patients in prolonged weaning. Proceedings of the 18th International Symposium on Cardiorespiratory Physiotherapy and Physiotherapy in Intensive Care Therapy. Belo Horizonte, Minas Gerais, Brazil. 7: 24.

30. de Souza LC, Campos JFR, Daher LP, da Silva PF, Ventura A, et al. (2014) Mechanical Ventilation Weaning in Inclusion Body Myositis: Feasibility of Isokinetic Inspiratory Muscle Training as an Adjunct Therapy. Case Rep Crit Care: 902541 